\section{Interpretation of Light Quality Measurements and Plant Response in Spectral Filter Research}

\author{
Nihal C. Rajapakse ${ }^{1}$, Robert K. Pollock ${ }^{2}$, Margaret J. McMahon ${ }^{1}$, \\ John W. Kelly ${ }^{1}$, and Roy E. Young ${ }^{2}$ \\ Clemson University Clemson, SC 29634-0375
}

Additional index words. photomorphogenesis, red light, far-red light, phytochrome, $\mathrm{R}$ : FR ratio, phytochrome photoequilibrium, chrysanthemum, Dendrathema $\times$ grandiflorum

Abstract. Experiments were conducted to correlate the response of chrysanthemum [Dendrathema xgrandiflorum (Ramat.) Kitamura] plants to light environment based on various quantitative light quality parameters by growing plants under $6 \%$ or $40 \%$ $\mathrm{CuSO}_{4}$ and water spectral filters. Using a narrow band width $(\mathrm{R}=655-665$ and $\mathrm{FR}$ $=725-735 \mathrm{~nm})$ or a broad band width $(R=600-700$ and $F R=700-800 \mathrm{~nm})$ for $R$ : FR ratio calculation, $6 \% \mathrm{CuSO}_{4}$ filter transmitted light with a higher $\mathrm{R}:$ FR ratio than $40 \% \mathrm{CuSO}_{4}$ or water filters. Light transmitted through $40 \% \mathrm{CuSO}_{4}$ and water filters had similar narrow band $R: F R$ ratios $(\approx 1.2)$, but the broad band $R: F R$ ratio (2.0) of $40 \% \mathrm{CuSO}_{4}$ filter was higher than that of water filters. The estimated phytochrome photoequilibrium $(\phi)$ value varied considerably with the photochemical properties of phytochrome used for estimations. Final height and internode length of plants grown in $6 \%$ or $40 \% \mathrm{CuSO}_{4}$ chambers was $\approx 30 \%$ less than of plants in corresponding control chambers. Leaf and stem dry weights were reduced by light transmitted through $\mathrm{CuSO}_{4}$ filters. The results suggest that broad band $\mathrm{R}:$ FR ratio correlated more closely to above plant responses than the narrow band $R:$ FR ratio. Blue (B) : $R$ and $B$ : FR ratios (not absolute amount of blue wavelengths) correlated well with plant response, suggesting that involvement of blue light should not be ignored in expressing plant response to light transmitted through $\mathrm{CuSO}_{4}$ filters. At present, the presentation of complete spectral data would be the most useful in explaining plant response to light environment.

Despite the increasing interest in the physiological responses of plants to variations in light quality, comprehensive agreement on a numerical parameter for correlating plant response and light quality has not emerged from the literature. The most complete method would be the presentation of the entire spectral profiles, but this method lacks the conciseness and precision of quantitative measurements such as $\mathrm{R}$ : FR ratio, estimates of phytochrome photoequilibrium $(\phi)$ [i.e., the amount of phytochrome present in FR absorbing form $\left(\mathrm{P}_{\mathrm{fr}}\right)$ relative to total phytochrome $\left(\mathrm{P}_{\text {tot }}\right)$ ], or phytochrome cycling rate (i.e., phytochrome interconversion relative to specific spectral quality and irradiance). At present, the numbers being used to compare plant responses to light environment vary considerably and rely on the preference of the researcher.

The R : FR ratio for a given light source varies with the wavelengths selected to represent $\mathrm{R}$ and FR measurements; a wide range of wavelengths has been used for R : FR

Received for publication 30 Sept. 1991. Accepted for publication 30 June 1992. Technical contribution no. 3228 of the South Carolina Agricultural Experiment Station. The cost of publishing this paper was defrayed in part by the payment of page charges. Under postal regulations, this paper therefore must be hereby marked advertisement solely to indicate this fact.

${ }^{1}$ Dept. of Horticulture.

${ }^{2}$ Dept. of Agricultural and Biological Engineering. acting effects of wavelengths (350 to $\mathrm{nm}$ ) in phytochrome photoconversion (Kelly and Lagarias, 1985; Sager et al., 1988). The estimates of $\phi$ are derived from measured optical properties of purified phytochrome over a broad spectrum (i.e., from 350 to 850 $\mathrm{nm})$. Methods for estimating $\phi$ from spectroradiometeric data have been described by several researchers (Gardner and Graceffo, 1982; Kelly and Lagarias, 1985; Sager et al., 1988). Smith and Holmes (1977), however, suggested that $\phi$ can be accurately estimated from $\mathrm{R}$ : FR ratio, because established $\phi$ is mainly related to the energy in $R$ and FR wavelengths. Pratt and Briggs (1966), on the other hand, have shown that phytochrome undergoes absorbance changes in blue wavelengths, indicating that phytochrome transformation may be sensitive to blue wavelengths of the spectrum. Because of the variations in $\mathrm{R}$ : FR ratio and $\phi$, it is difficult to select a numerical quantifier for correlating plant response to a given light environment.

The difficulties in correlating quantitative light quality parameters and plant response emerged as a result of experiments conducted to explore the use of spectral filters for plant growth regulation as an alternative means to the use of chemical growth regulators. In our previous work, light transmitted through $6 \% \mathrm{CuSO}_{4}$ filters produced short, compact plants similar in appearance to plants treated with chemical growth regulators, such as daminozide (Rajapakse and Kelly, 1991). However, light measurements under several $\mathrm{CuSO}_{4}$ solutions indicated that the spectral quality and quantitative light quality parameters varied with $\mathrm{CuSO}_{4}$ concentration.

The objectives of this experiment were to determine if chrysanthemum plants grown under $6 \%$ and $40 \% \mathrm{CuSO}_{4}$ filters (which gave different spectral characteristics of transmitted light) have similar morphology and to correlate the response of chrysanthemum to several quantitative light quality parameters.

Determination of spectral quality. The spectral energy flux ( 350 to $850 \mathrm{~nm}$ in $5-\mathrm{nm}$ increments) of sunlight transmitted through double-layered polycarbonate panels (with 6 $\times 11-\mathrm{mm}$ channels) filled with $0 \%$ [water (control)], 2\%, 4\%, 6\%, 8\%, 10\%, 15\%, $20 \%, 30 \%$, or $40 \% \mathrm{CuSO}_{4} \cdot 5 \mathrm{H}_{2} \mathrm{O}$ solutions was measured on a clear day between 1200

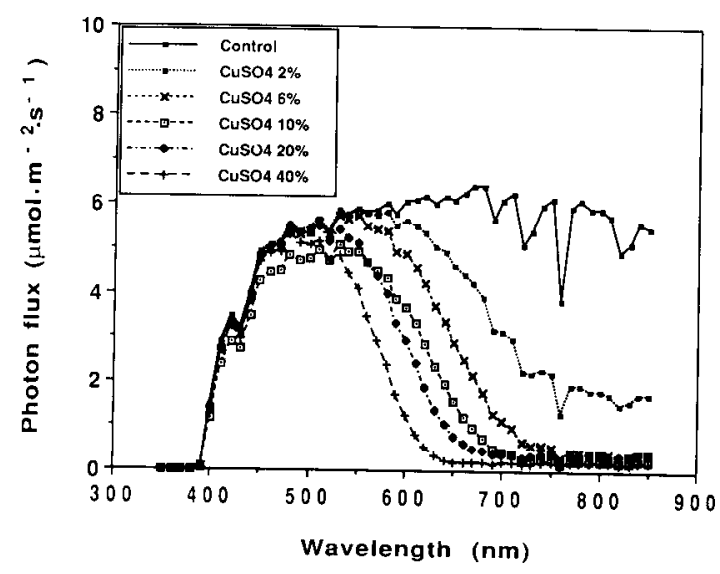

Fig. 1. Spectral distribution curves for $0 \%$ (control), $2 \%, 6 \%, 10 \%, 20 \%$, and $40 \% \mathrm{CuSO}_{4}$ filters. 
Table 1. Variation in red : far red (R : FR) ratio, as influenced by band width, and blue : red (B : R) and B : FR ratios of light transmitted through $\mathrm{CuSO}_{4}$ filters.

\begin{tabular}{lccccc}
\hline \hline $\begin{array}{l}\mathrm{CuSO}_{4} \\
\text { concn } \\
(\%)\end{array}$ & \multicolumn{3}{c}{$\mathrm{R}: \mathrm{FR}^{2}$} & & \\
\cline { 2 - 4 } & $\mathrm{NB1}$ & $\mathrm{NB2}$ & $\mathrm{BB}$ & $\mathrm{B}: \mathrm{R}^{\mathrm{y}}$ & $\mathrm{B}: \mathrm{FR}^{\mathrm{x}}$ \\
\hline 0 & 1.1 & 1.2 & 1.1 & 0.7 & 0.9 \\
2 & 1.9 & 2.1 & 2.1 & 1.0 & 2.0 \\
4 & 2.8 & 3.4 & 3.3 & 1.2 & 4.1 \\
6 & 4.0 & 5.0 & 5.2 & 1.4 & 7.7 \\
8 & 4.7 & 6.1 & 6.4 & 1.7 & 11.6 \\
10 & 4.7 & 6.3 & 6.7 & 2.1 & 14.0 \\
15 & 3.5 & 5.6 & 6.0 & 3.2 & 19.1 \\
20 & 1.7 & 2.7 & 3.0 & 3.8 & 14.0 \\
30 & 1.3 & 1.7 & 2.8 & 7.7 & 18.6 \\
40 & 1.1 & 1.3 & 2.0 & 11.4 & 20.9 \\
\hline
\end{tabular}

${ }^{\mathrm{z}} \mathrm{NB} 1$ = narrow band $\mathrm{R}$ : $\mathrm{FR}$ ratio using $\mathrm{R}=$ 655-665 nm and FR = 725-735 nm (Smith, 1982). $\mathrm{NB} 2=$ narrow band $\mathrm{R}:$ FR ratio using $\mathrm{R}=640$ $650 \mathrm{~nm}$ and FR $=725-735 \mathrm{~nm}$ (Kaspcrbauer et al., 1963). $\mathrm{BB}=$ broad band $\mathrm{R}$ : FR ratio using $\mathrm{R}=600-700 \mathrm{~nm}$ and $\mathrm{FR}=700-800 \mathrm{~nm}$ (Mortenson and Stromme, 1987).

${ }^{y_{B}}$ : $R$ ratio using $\mathrm{B}=400-500 \mathrm{~nm}$ and $\mathrm{R}=$ 600-700 nm.

${ }^{\mathrm{x}} \mathrm{B}$ : FR ratio using $\mathrm{B}=400-500 \mathrm{~nm}$ and $\mathrm{FR}=$ $700-800 \mathrm{~nm}$

Table 2. Variation in estimated phytochrome photoequilibrium ( $\varnothing)$ of light transmitted through $\mathrm{CuSO}_{4}$ filters using different photochemical properties of phytochrome.

\begin{tabular}{lccc}
\hline \hline $\begin{array}{l}\mathrm{CuSO}_{4} \\
\text { concn } \\
(\%)\end{array}$ & \multicolumn{3}{c}{$\emptyset^{x}$} \\
\cline { 2 - 4 } & SSEC & $\mathrm{K} \& \mathrm{~L}$ & $\mathrm{G} \& \mathrm{G}$ \\
\hline 0 & 0.72 & 0.71 & 0.55 \\
2 & 0.77 & 0.76 & 0.61 \\
4 & 0.80 & 0.79 & 0.65 \\
6 & 0.81 & 0.80 & 0.67 \\
8 & 0.81 & 0.80 & 0.69 \\
10 & 0.80 & 0.80 & 0.70 \\
15 & 0.79 & 0.78 & 0.70 \\
20 & 0.76 & 0.75 & 0.67 \\
30 & 0.73 & 0.72 & 0.65 \\
40 & 0.70 & 0.70 & 0.63 \\
\hline
\end{tabular}

${ }^{\mathrm{z}} \mathrm{SSEC}, \mathrm{D} \& \mathrm{~L}$, and G\&G represent $\emptyset$ values estimated by Sager et al. (1988), Kelly and Lagarias (1985), and Gardner and Graceffo (1982) methods, respectively.

Table 3. Influence of control (cont.) and $\mathrm{CuSO}_{4}$ filters on leaf area and internode length.

\begin{tabular}{|c|c|c|c|}
\hline $\begin{array}{l}\mathrm{CuSO}_{4} \\
\text { concn }\end{array}$ & $\begin{array}{c}\text { Shade } \\
(\%)\end{array}$ & $\begin{array}{c}\text { Plant } \\
\mathrm{ht} \\
(\mathrm{cm})\end{array}$ & $\begin{array}{l}\text { Internode } \\
\text { length } \\
(\mathrm{cm})\end{array}$ \\
\hline 0 (cont. 1$)$ & 37 & 34.8 & 1.8 \\
\hline (cont. 2) & 58 & 32.3 & 1.6 \\
\hline $6 \%$ & 37 & 24.4 & 1.2 \\
\hline $40 \%$ & 58 & 21.6 & 1.1 \\
\hline \multicolumn{4}{|l|}{ Contrasts ${ }^{2}$} \\
\hline $6 \% \mathrm{CuSO}_{4}$ vs. cont. 1 & & $* * *$ & $* * *$ \\
\hline $40 \% \mathrm{CuSO}_{4}$ vs. contl. 2 & & $* * *$ & $* * *$ \\
\hline Cont. 1 vs. cont. 2 & & $*$ & $*$ \\
\hline $\mathrm{CuSO}_{4} 6 \%$ vs. $40 \%$ & & ** & * \\
\hline
\end{tabular}

${ }^{\mathrm{z}}$ Single-degree-of-freedom contrasts.

***,***Significant at $P=0.05,0.01$, or 0.001 , respectively. and $1400 \mathrm{HR}$ with a LI-1800 spectroradiometer fitted with a LI-1800-10 remote cosine sensor (LI-COR, Lincoln, Neb.). The procedure was repeated on another clear day. Photosynthetic photon flux (PPF) of transmitted light was determined as photon flux (PF) integrated between 400 and $700 \mathrm{~nm}$. Percent shading (in 400-700 $\mathrm{nm}$ range) by $\mathrm{CuSO}_{4}$ solutions was determined by comparing them with irradiance under the water (control) panel. The $\mathrm{R}$ : FR ratio of transmitted light was determined as the ratio of $\mathrm{PF}$ between 655 and $665 \mathrm{~nm}(\mathrm{R})$ and 725 and $735 \mathrm{~nm}$ (FR) (narrow band R : FR) and as the ratio of $P F$ between 600 and $700 \mathrm{~nm}$ (R) and 700 and $800 \mathrm{~nm}$ (FR) (broad band $\mathrm{R}: \mathrm{FR})$. In addition, blue $: \operatorname{red}(\mathrm{B}: \mathrm{R})$ and blue : far red (B : FR) ratios were determined as ratio of PF between wavelengths 400 and $500 \mathrm{~nm}$ (B), 600 and $700 \mathrm{~nm}, 400$ and 500 $\mathrm{nm}$, and 700 and $800 \mathrm{~nm}$, respectively. Phytochrome photoequilibrium under spectral filters was estimated using spectroradiometric data and phytochrome properties described by Gardner and Graceffo (1982), Kelly and Lagarias (1985), and Sager et al. (1988). Gardner and Graceffo (1982) used etiolated corn (Zea mays L.) coleoptiles to determine an in vivo action spectrum for phytochrome transformation, and $\phi$ was determined as the sum of the product of photon fluence rate (PFR) of the light source and the relative quantum efficiency of phytochrome phototransformation. Kelly and Lagarias (1985) and Sager et al. (1988) used purified phytochrome from etiolated oat and rye (Secale cereale L.) tissues to determine in vitro action spectra, and $\phi$ was determined as the sum of the product of PFR and the photochemical cross sections of phytochrome.

Evaluation of plant growth. Rooted 'Bright Golden Anne' chrysanthemum shoot cuttings with three to four leaves (Yoder Bros., Pendleton, S.C.) were planted (Sept. 1990) in 0.6-liter square plastic pots containing a commercial potting mix (Mix 3B, Fafard Inc., Anderson, S.C.). After a 1-week establishment period, plants were transferred to four growth chambers, one each with $6 \%$ or $40 \%$ $\mathrm{CuSO}_{4} \cdot 5 \mathrm{H}_{2} \mathrm{O}$ and two with water (control) "fluid roofs" (Rajapakse and Kelly, 1992) placed inside a glass greenhouse. Light transmission into the chamber only occurred through the fluid roof. PPF under $6 \%$ and $40 \% \mathrm{CuSO}_{4}$ filters was reduced by $\approx 37 \%$ and $58 \%$, respectively, of natural light in the greenhouse, which averaged $\approx 1500$ $\mu \mathrm{mol} \cdot \mathrm{m}^{-2} \cdot \mathrm{s}^{-1}$. A neutral shading material (cheesecloth) was used in each control to ensure the same PPF level as in the corresponding $\mathrm{CuSO}_{4}$ chamber. Plants were irrigated once daily with $18 \mathrm{~N}-3.5 \mathrm{P}-5 \mathrm{~K} \mathrm{mM}$ from Peter's 20-20-20 fertilizer (W.R. Grace, Fogelsville, Pa.). Average daily maxima inside $6 \%$ and $40 \% \mathrm{CuSO}_{4}$ chambers were $30 \pm$ $4 \mathrm{C}$ and $27 \pm 3 \mathrm{C}$, respectively, and the minimum was $18 \pm 4 \mathrm{C}$ for both.

At the end of the 4-week growing period, plant height (height from soil level to apex), number of fully expanded leaves, and leaf and stem dry weights were recorded. For dry weight measurements, tissue was oven dried at $85 \mathrm{C}$ for $48 \mathrm{~h}$. Average internode length was estimated as plant height/number of leaves.

The experiment was repeated once. Four light treatments were randomly assigned to chambers with five plants per treatment. Data were subjected to analysis of variance. Differences among means were tested using single-degree-of-freedom contrasts.

$\mathrm{CuSO}_{4}$ solutions reduced both $\mathrm{R}$ (600-700 $\mathrm{nm})$ and FR (700-800 nm) wavelengths of transmitted light, but the reduction of FR was much greater than the reduction of $\mathrm{R}$ wavelengths (Fig. 1). Increasing $\mathrm{CuSO}_{4}$ concentration from $0 \%$ to $10 \%$ reduced transmission of most of the FR wavelengths. Further increase in $\mathrm{CuSO}_{4}$ concentration (from $10 \%$ to $40 \%$ ) reduced transmission of $\mathrm{R}$ wavelengths. Photon flux in the $\mathrm{B}$ wavelengths (400-500 $\mathrm{nm}$ ) was relatively unaffected by $\mathrm{CuSO}_{4}$ filters.

$\mathrm{R}$ : FR ratio varied considerably with the band width selection (Table 1 ). $\mathrm{R}$ : FR ratio under $\mathrm{CuSO}_{4}$ filters was slightly higher when calculated using broad band widths than narrow band widths. Both narrow and broad band $\mathrm{R}$ : FR ratios increased as $\mathrm{CuSO}_{4}$ concentration increased from $0 \%$ to $10 \%$ due to relatively greater reduction of FR wavelengths of transmitted light. Further increase of $\mathrm{CuSO}_{4}$ concentration reduced $\mathrm{R}$ : FR ratio due to continued reduction of $R$ wavelengths. The narrow band $\mathrm{R}$ : FR ratio of light under $40 \% \mathrm{CuSO}_{4}$ filter was similar to that of the control (water) due to reduction of $\mathrm{R}$ wavelengths above $640 \mathrm{~nm}$; the broad band $\mathrm{R}$ : FR ratio, however, was slightly higher under $40 \% \mathrm{CuSO}_{4}$ than under the control. $\mathrm{B}$ : $\mathrm{R}$ and $\mathrm{B}$ : FR ratios increased as the concentration of $\mathrm{CuSO}_{4}$ increased because of the relatively unchanged $\mathrm{PF}$ in $\mathrm{B}$ wavelengths and large reductions of $\mathrm{R}$ and FR wavelengths of transmitted light with increasing concentration (Table 1). The highest B : R or B : FR ratios were under $40 \%$ $\mathrm{CuSO}_{4}$ filter.

In general, the estimated $\phi$ light transmitted through $\mathrm{CuSO}_{4}$ filters increased as concentration increased from $0 \%$ to $\approx 10 \%$ and decreased thereafter (Table 2). The estimated values of $\phi$ using the methods described by Sager et al. (1988; SSEC) and Kelly and Lagarias (1985; K\&L) were not significantly different from each other but higher than the values estimated using the Gardner and Graceffo (1982; G\&G) method. The estimated $\phi$ for light transmitted through $40 \% \mathrm{CuSO}_{4}$ filter (0.70) was slightly lower than that for the control (water) filter $(\approx 0.71)$ when calculated using the SSEC or K\&L methods; however, when calculated using the G\&G method, light transmitted through $40 \%$ $\mathrm{CuSO}_{4}$ filter had a higher estimate for $\phi(0.63)$ than the control filter (0.55). Generally, estimated values of $\phi$ were slightly higher when calculated by using the method described by SSEC or K\&L than by that of G\&G.

In our previous experiments, we noted that the plants grown under $\mathrm{CuSO}_{4}$ filters $(4 \%$, $6 \%, 8 \%$, or $16 \% \mathrm{CuSO}_{4}$ ) were significantly 
Table 4. Influence of control (cont.) and $\mathrm{CuSO}_{4}$ filters on leaf and stem dry weights. Number in parentheses indicates the percentage of total dry weight accumulated in leaves or stems.

\begin{tabular}{|c|c|c|c|c|}
\hline \multirow{2}{*}{$\begin{array}{l}\mathrm{CuSO}_{4} \\
\text { concn }\end{array}$} & \multirow{2}{*}{$\begin{array}{c}\text { Shade } \\
(\%)\end{array}$} & \multicolumn{3}{|c|}{ Dry wt $(\mathrm{g})$} \\
\hline & & Total & Leaf & Stem \\
\hline 0 (cont. 1) & 37 & 3.5 & $2.3(66)$ & $1.2(34)$ \\
\hline (cont. 2) & 58 & 3.1 & $2.2(71)$ & $0.9(29)$ \\
\hline $6 \%$ & 37 & 2.5 & $2.0(80)$ & $0.5(20)$ \\
\hline $40 \%$ & 58 & 1.9 & $1.5(79)$ & $0.4(21)$ \\
\hline \multicolumn{5}{|l|}{ Contrasts ${ }^{2}$} \\
\hline $6 \% \mathrm{CuSO}_{4}$ vs. cont. 1 & & $* * *$ & $* *$ & $* * *$ \\
\hline $40 \% \mathrm{CuSO}_{4}$ vs. cont. 2 & & $* * *$ & $* * *$ & $* * *$ \\
\hline Cont. 1 vs. cont. 2 & & * & NS & ** \\
\hline $\mathrm{CuSO}_{4} 6 \%$ vs. $40 \%$ & & $* * *$ & $* * *$ & ** \\
\hline
\end{tabular}

${ }^{\mathrm{z}}$ Single-degree-of-freedom contrasts.

NS,$* * * * * *$ Nonsignificant or significant at $P=0.05,0.01$, or 0.001 , respectively.

shorter than plants grown under water filters (Rajapakse and Kelly, 1991, 1992). Light transmitted through $4 \%, 6 \%, 8 \%$, or $16 \%$ $\mathrm{CuSO}_{4}$ filters had higher narrow or broad band R : FR ratios and higher estimates for $\phi$ (using any of the above methods) than the control; therefore, plant height reduction under these filters was attributed to a higher $\mathrm{R}$ : FR ratio and higher $\phi$. Spectral data in this study indicated that light transmitted through $40 \% \mathrm{CuSO}_{4}$ filter had a similar narrow band $\mathrm{R}$ : FR ratio and slightly lower $\phi$ than that of the control when calculated using the method of SSEC or K\&L. However, broad band R : FR ratio and estimated $\phi$ using the G\&G method were higher for light transmitted through $40 \% \mathrm{CuSO}_{4}$ than the control filter. Because of the variability in these quantitative estimates for light quality under $40 \% \mathrm{CuSO}_{4}$ and control filters, we decided to compare the morphology of chrysanthemum plants grown under $40 \% \mathrm{CuSO}_{4}$ to those grown under $6 \% \mathrm{CuSO}_{4}$, which has already been shown to alter morphology (Rajapakse and Kelly, 1991).

Final height of plants grown under $6 \%$ and $40 \% \mathrm{CuSO}_{4}$ filters was $\approx 30 \%$ and $33 \%$ less than that of plants grown under corresponding control filters (Table 3). A height difference between plants grown under $\mathrm{CuSO}_{4}$ and control filters was visible within 1 week after treatment and the difference increased as exposure time increased (data not shown). Plants receiving more PPF were significantly taller than plants receiving lower PPF in both control and $\mathrm{CuSO}_{4}$ treatments.

There were 19 or 20 leaves per plant, regardless of treatments (difference NS at $P=$ 0.05 ). Light under $6 \%$ and $40 \% \mathrm{CuSO}_{4}$ filters resulted in about $31 \%$ and $33 \%$ reduction in average internode length, respectively.

Total shoot dry weight was reduced under $\mathrm{CuSO}_{4}$ filters compared to corresponding control filters. Total dry weight reduction (39\%) under the $40 \% \mathrm{CuSO}_{4}$ filter was greater than that under the $6 \% \mathrm{CuSO}_{4}$ filter $(28 \%)$ (Table 4). Both leaf and stem dry weights were reduced by light in $\mathrm{CuSO}_{4}$ chambers compared with the corresponding control. The reduction of stem dry weight was greater than the reduction of leaf dry weight. Leaf dry weight reduction $(32 \%)$ was greater under $40 \% \mathrm{CuSO}_{4}$ filter than under $6 \% \mathrm{CuSO}_{4}$ filter $(13 \%)$. Stem dry weight reduction was basically unchanged for the $6 \%$ and $40 \%$ $\mathrm{CuSO}_{4}$ filters (56\% and $58 \%$, respectively). $\mathrm{CuSO}_{4}$ filters reduced percent dry matter accumulation into stems (from $\approx 31 \%$ to $\approx 20 \%$ ) and increased it into leaves (from $\approx 70 \%$ to $\approx 80 \%$ ) (Table 4).

Light transmitted through $6 \%$ or $40 \%$ $\mathrm{CuSO}_{4}$ filters had similar effects on plant morphology. In our previous experiments, we showed that $6 \% \mathrm{CuSO}_{4}$ spectral filters reduced plant height, internode length, growth rate, and total dry weight of chrysanthemum. These responses were attributed to the high $\mathrm{R}$ : FR ratio and $\phi$ of transmitted light (Rajapakse and Kelly, 1992). Light high in $R$ wavelengths shifts $\phi$ toward production of more $\mathrm{P}_{\mathrm{fr}}$, which is assumed to be the active form in controlling plant responses. Light high in $R$ relative to $F R$ wavelengths has been reported to reduce stem elongation of maize (Vanderhoef et al., 1979) and reduce stem dry weight of tomato (Lycopersican esculentum Mill.) (Hurd, 1974).

Although most of the research on light quality and plant responses has focused on $\mathrm{R}$ : FR ratios and $\phi$, involvement of $\mathrm{B}$ light in regulation of plant response under $\mathrm{CuSO}_{4}$ filters cannot be neglected. Blue light has been shown to reduce stem elongation, and FR light in combination with B light has been shown to reverse B-light-induced responses (Kadman-Zahavi and Ephrat, 1976). Red light, in the absence of $\mathrm{B}$, may not be effective in reducing stem elongation (McMahon et al., 1991). Therefore, B light, acting on the phytochrome system or through a blue light receptor, might have elicited the observed reduction in plant height and internode length under the $\mathrm{CuSO}_{4}$ filter. $\mathrm{CuSO}_{4}$ filters used in this study did not significantly alter PF in B wavelengths (400-500 nm). Because of the relatively unchanged B wavelengths and continued reduction of $\mathrm{R}$ and $\mathrm{FR}$ wavelengths, ratios of $\mathrm{B}: \mathrm{R}$ and $\mathrm{B}: \mathrm{FR}$ of transmitted light increased as the $\mathrm{CuSO}_{4}$ concentration increased from $0 \%$ to $40 \%$; light under $40 \% \mathrm{CuSO}_{4}$ had the highest $\mathrm{B}: \mathrm{R}$ or $\mathrm{B}$ : FR ratio (Table 1). The morphological differences observed under $6 \%$ and $40 \%$ $\mathrm{CuSO}_{4}$ filters could be better explained (higher correlation) by the higher $\mathrm{B}: \mathrm{R}$ or $\mathrm{B}: \mathrm{FR}$ ratios of transmitted light under these filters. In this study, both control and $\mathrm{CuSO}_{4}$ filters had about the same amount of PF in B wave- lengths, but the amount of B wavelengths relative to $\mathrm{R}$ or $\mathrm{FR}$ wavelengths was much higher under $\mathrm{CuSO}_{4}$ filters. The amount of $B$ wavelengths relative to $R$ or FR wavelengths in light possibly may be more important in regulating the plant response than the absolute amount of $\mathrm{B}$ wavelengths received by the plant.

$\mathrm{R}$ : FR red ratio and estimates of $\phi$ in a given light environment vary considerably with the wavelengths and the photochemical properties of phytochrome used in the calculations. Based on narrow band $\mathrm{R}$ : FR ratio or $\phi$ estimated by the Sager et al. (1988) or Kelly and Lagarias (1985) method, one would expect no difference in plant height between $40 \% \mathrm{CuSO}_{4}$ and the control filter. However, $40 \% \mathrm{CuSO}_{4}$ filters reduced plant height and internode length, although narrow band $\mathrm{R}$ : FR ratio and $\phi$ values were similar to those of the control filter. This result suggests that these two quantitative light quality parameters did not correlate well with the plant response observed under $40 \% \mathrm{CuSO}_{4}$ filter. The broad band $\mathrm{R}$ : FR ratio and $\phi$ estimated using the Gardner and Graceffo (1982) method, however, were better correlated with the morphological differences observed between control and $\mathrm{CuSO}_{4}$ filters. The data also suggest that involvement of B light should not be ignored in expressing plant response to light quality.

\section{Literature Cited}

Gardner, G. and M.A. Graceffo. 1982. The use of a computerized spectroradiometer to predict phytochrome photoequilibria under polychromatic irradiation. Photochem. Photobiol. 36:349354.

Hurd, R.G. 1974. The effect of an incandescent supplement on the growth of tomato plants in low light. Ann. Bot. 38:613-623.

Kadman-Zahavi, A. and E. Ephrat. 1976. Development of plants in filtered sunlight. II. Effects of spectra! composition, light intensity, day length, red and far-red irradiations on long- and short-day grasses. Israel J. Bot. 25:11-23.

Kasperbauer, M.J., H.A. Borthwick, and S.B. Hendricks. 1963. Inhibition of flowering of Chenopodium rubrum by prolonged far-red radiation. Bot. Gaz. 124:444-451.

Kelly, J.M. and J.C. Lagarias. 1985. Photochemistry of 124-kilodalton Avena phytochrome under constant illumination in vitro. Biochemistry 24:6003-6010.

McMahon, M.J., J.W. Kelly, D.R. Decoteau, R.K. Pollock, and R.E. Young. 1991. Growth of Dendranthema x grandiflorum (Ramat.) Kitamura under various spectra! filters. J. Amer. Soc. Hort. Sci. 116:950-954.

Mortensen, L.M. and E. Stromme. 1987. Effects of light quality on some greenhouse crops. Scientia Hort. 33:27-36.

Pratt, L.H. and W.R. Briggs. 1966. Photochemical and nonphotochemical reactions of phytochrome in vivo. Plant Physiol. 41:467-474.

Rajapakse N.C. and J.W. Kelly. 1991. Influence of $\mathrm{CuSO}_{4}$ spectral filters, daminozide and exogenous gibberellic acid on Dendranthema $\times$ grandiflorum (Ramat.) Kitamura growth. J. Plant Growth Regulat. 10:207-214.

Rajapakse N.C. and J.W. Kelly. 1992. Regulation of chrysanthemum growth by spectral filters. J. Amer. Soc. Hort. Sci. 117:481-485.

Sager, J.C., W.O. Smith, J.C. Edwards, and K.L. 
Cyr. 1988. Photosynthetic efficiency and phytochrome photoequilibria determination using spectral data. Trans. Amer. Soc. Agr. Eng. 31:1882-1887.

Smith, H. 1982. Light quality, photoperception, and plant strategy. Ann. Rev. Plant Physiol. 33:481-518.

Smith, H. and M.G. Holmes. 1977. The function of phytochrome in the natural environment. III. Measurement and calculation of phytochrome photoequilibrium. Photochem. Photobiol. 25:547-550.

Vanderhoef, L.N., P.H. Quail, and W.R. Briggs. 1979. Red light-inhibited mesocotyl elongation in maize seedlings. Plant Physiol. 63:1062-1067. 